\title{
Artigo
}

\section{A ideia de método na Teoria Política Normativa}

\author{
The idea of method in Normative Political Theory
}

\author{
Lucas Suárez de Oliveira Tozo \\ Doutorando em Ciência Política, Universidade Estadual de \\ Campinas (UNICAMP), Campinas, SP, Brasil \\ lucastozo@gmail.com
}

\begin{abstract}
Resumo: É comum na teoria política normativa o silêncio no que tange ao "método" ou a natureza da disciplina. Sendo assim, podemos falar em método na teoria política normativa? É em busca de uma resposta a esta questão que se debruça o presente trabalho. Partindo de uma distinção de Gilles G. Granger entre a ideia de método como algoritmo ou como estratégia/estilo, e de uma análise pontual da teoria política normativa analítica, propomos, considerando a natureza filosófica da disciplina, que a ideia de método pertinente a esta é a do método como estratégia/estilo.
\end{abstract}

Palavras-chave: Método; Teoria política normativa; Filosofia política; Método em teoria políica.

\begin{abstract}
Silence regarding "method" or the nature of discipline in the Normative Political Theory is rather common. Is it possible, then, to discuss method in Normative Political Theory? The present work is dedicated to pursuing an answer to this question. We part from Gilles G. Granger's distinction between the ideas of method as algorithm and strategy/style along with a careful analysis of analytic normative political theory to propose that, according to the philosophic nature of the discipline, the most pertinent idea of method in this case is the strategy/style one.
\end{abstract}

Keywords: Method; Normative political theory; Political philosophy; Method in political theory. 


\section{Introdução}

É comum na teoria política o silêncio no que tange ao "método" ou a natureza da disciplina. Enquanto em outras áreas da ciência política e das ciências sociais encontramos uma grande energia nesta discussão - evidenciada pela vasta literatura sobre o assunto -, os que lidam com a teoria política, como nos fala uma das escassas obras específicas sobre o tema, raramente abordam questões do "como"e do "porquê" em seus trabalhos (LEOPOLD; STEARS, 2008, p. 1). É comum que os teóricos políticos permaneçam imperturbados a esse respeito: o importante em teoria política é apenas fazê-la (VINCENT, 2004, p. 1).

É claro que existem exceções. De acordo com uma visão comum, a disciplina de teoria política é bifurcada em "filosofia política contemporânea" (ou teoria política normativa) e"história do pensamento político"(FRAZER, 2010, p. 2). Nesta segunda linha, podemos encontrar uma grande quantidade de textos metodológicos exemplificados nos trabalhos de Quentin Skinner, J. G. Pocock e R. Koselleck; interessantemente, como pontua Michael Frazer (2010, p. 2), não encontramos a mesma intensidade de debate no primeiro subcampo. Em todo caso, o aparecimento de mais literatura específica como a de Jonathan Floyd e Marc Stears (FLOYD; STEARS 2011), Valentini (2012), List e Valentini (2016) e no caso brasileiro, pela primeira vez de um curso dedicado ao tema', parecem indicar uma agenda emergente, ou, na expressão de Laura Valentini (2012, p. 654) um "methodological turn".

A importância deste debate é clara se pensarmos na mudança qualitativa que uma maior compreensão das expectativas dos praticantes e um senso firme do que é uma pesquisa bem-sucedida podem trazer para a disciplina. Ao final, a questão não é entre ter um método ou não, mas entre pensar no método ou simplesmente produzir irrefletidamente acerca dos pressupostos que informam a prática na área (LEOPOLD; STEARS, 2008, p. 2; VINCENT, 2004, p. 10).

Sendo assim, formulamos a seguinte questão: podemos falar em método na teoria política normativa? Nossa posição é a de que podemos, mas não em um método científico.

1 Faço referência ao módulo "Methods and problems in political philosophy" oferecido pela professora Herlinde Pauer-Studer da Universidade de Viena, durante a 6th Annual Summer School da International Political Science Association - IPSA realizada em janeiro e fevereiro de 2015 na Universidade de São Paulo - USP. 
Para construir o nosso argumento, partiremos do exame de uma distinção proposta por Gilles-Gaston Granger; em seguida, examinaremos a noção de "teoria política normativa" (em especial a vertente analítica), para então, examinarmos a questão do método nesta disciplina, à luz da distinção referida, e oferecermos nossas conclusões.

\section{Duas ideias de método e a Teoria Política Normativa}

Segundo Gilles-Gaston Granger (1992, p. 55-56), de forma abrangente, um método consiste em todo percurso orientado para certo fim em que se fazem presentes as seguintes características: (a) um método consiste em seguir regras fundamentalmente associadas a certa ideia de eficácia; (b) procura a economia de esforços, estabiliza a ação oferecendo o ponto de apoio; (c) o método é essencialmente um meio para se combater o aleatório e (d) a ação metódica é cumulativa, permite crescer progressivamente em conhecimento ou obter resultados parciais.

Granger (1992, p. 58) também distingue dois polos irredutíveis da ideia de método, um correspondendo à noção de algoritmo, denotando a ideia de receita ou procedimento, que descrevem detalhadamente a concatenação do que deve ser feito; o outro correspondendo à noção de estratégia, que não fornece necessariamente uma indicação particularizada de atos a cumprir, mas somente o espírito dentro do qual a decisão deve ser tomada e as ações devem ocorrer.

Feita essa distinção, no quadro geral do conhecimento, conforme nos fala Isaiah Berlin (2002a, p. 100-102), existem pelo menos duas classes de problemas nas quais o homem tem obtido respostas claras: a primeira, referente ao domínio das ciências naturais, onde, em princípio, as respostas vêm da observação "organizada"; a segunda, referente ao domínio das ciências formais (e.g matemática, lógica formal), onde as respostas provém da dedução bem conduzida de axiomas. Nestes domínios encontramos o método como algoritmo tal qual nos fala Granger.

Ao lado dessas duas categorias, no entanto, existem questões que estão fora e não se encaixam em nenhuma delas, são as questões filosóficas, aquelas em que não dispomos de regras claras de como obter as respostas e onde procurar suas evidências (BERLIN, 2002a, p. 102). A essas pertencem as questões típicas da filosofia política ou 
teoria política normativa² - que entenderemos como expressões sinônimas -, questões que envolvem julgamento normativo e avaliativo (LIST; VALENTINI, 2016)³. A essa classe especial de questões, parece oportuno que se recorra à noção de método como estratégia (GRANGER, 1992, p. 58), o que analisaremos após algumas considerações sobre a disciplina teoria política normativa.

A expressão teoria política, quando usada de forma ampla, remete a uma variedade de tipos de teoria dentro da ciência política. Quando usada de forma específica, remete a uma disciplina comumente bifurcada em (a) teoria política normativa e (b) história do pensamento político; diferenciando-se, portanto, das (c) teorias políticas positivas ou empíricas (FRAZER, 2010, p. 2; GUNNELL, 1987, p. 388; HELD, 1991, p. 16-19; STOKER, 1995, p. 16-17).

As teorias empíricas, de forma genérica e simplista, concentram-se na construção de explicações baseadas em fatos observáveis, isto é, em estabelecer relações causais entre os fatores responsáveis (variáveis independentes) e o fenômeno a ser explicado (variáveis dependentes).

No âmbito da história do pensamento político, a teoria é vista como uma atividade de análise das obras clássicas com o fito de estabelecer o sentido original dos textos, recapturando assim, a visão da política de cada autor em contextos históricos distintos. Destacam-se nessa área visões metodológicas plurais acerca da interpretação histórica, alguns exemplos proeminentes são a "Escola de Cambridge" de Quentin Skinner e J. G. Pocock e a alemã "História dos Conceitos" (Begriffsgeschichte) de Reinhart Koselleck.

No presente trabalho, nosso foco pertence às teorias políticas normativas que, nas palavras de Isaiah Berlin (2002b, p. 228), envolvem “a descoberta, ou aplicação, de noções morais na esfera das relações políticas". Desse modo, a teoria política normativa aparece

2 Fazemos nossas as palavras de lan Shapiro (1990, p. 3, grifo do autor), para quem os termos são intercambiáveis: "as one who has been unable to make any systematic sense of the difference in meaning between political theory and political philosophy, I use these terms interchangeably throughout". Entre as supostas razões da diferença terminológica afiguram-se o fato da institucionalização da filosofia política como disciplina nos departamentos de ciência política na segunda metade do século XX (VINCENT, 1997, p. 16), denotando com a expressão "teoria normativa" uma espécie distinta de teorização sobre a política entre outras formas possíveis de teoria; e, ou, uma questão de preferência geográica, no caso, filosofia política na Europa, teoria política normativa nos Estados Unidos (LIST; VALENTINI, 2016, p. 530; VARGAS-MACHUCA, 2003, p. 47).

3 List e Valentini (2016, p. 535-536) distinguem entre um conteúdo normativo, quando um julgamento envolve um "operador deôntico" (e.g. deve, pode, permitido, obrigatório) e um conteúdo avaliativo, quando envolve predicados de avaliação como bom, ruim, melhor, pior, desejável, indesejável. 
como análise e promoção de conceitos, princípios e teorias", entre outros, sobre "direitos", "justiça", "igualdade" e "democracia". Nessa forma particular, a teoria assume a forma de filosofia prática5 (LIST; VALENTINI, 2016, p. 534-536; VINCENT, 2004, p. 1) e apresenta como abordagens dominantes as provenientes da Teoria Crítica alemã, associadas principalmente aos trabalhos de Jürgen Habermas, e as abordagens da filosofia política analítica ${ }^{6}$, forma dominante no contexto anglo-americano, associada principalmente a John Rawls. Será esta última forma nosso objeto de análise.

\section{A crise do pensamento normativo no paradigma positivista}

As raízes da teoria política normativa se encontram na longa história da filosofia política e moral que vêm desde a antiguidade ${ }^{8}$. Desde então, questões sobre a "boa" vida e da ordem política apta a promovê-la, ou, de outra forma, a busca de um ponto de referência moral segundo o qual nossas práticas políticas e instituições possam

4 É importante a diferenciação entre conceitos, princípios e teorias e suas respectivas justificações e evidências. Segundo List e Valentini (2016, p. 535), conceitos servem para classificar/organizar objetos, não podem ser "verdadeiros" ou "falsos", mas "úteis/inúteis", mais ou menos "plausíveis". Como exemplo, List e Valentini observam que os conceitos de "vermelho","triângulo" ou "verde", não são verdadeiros ou falsos, tão somente quando estão presentes em afirmações: "tomates são vermelhos" (verdadeiro) ou neve é verde (falso). Em posse de um conceito, por exemplo, de "democracia" para identificarmos quando um sistema político conta como democrático, restará a questão de sua desejabilidade. É para responder a esta questão que necessitamos de princípios e teorias que nos informem, ainda no exemplo dado, que devemos ter decisões democráticas e o porquê. Sendo assim, sob a forma de proposições, princípios e teorias podem, ao contrário dos conceitos, serem qualificadas de verdadeiras/falsas. Poderíamos objetar, argumentam List e Valentini, com um exemplo como "liberdade como não interferência é a verdadeira concepção de liberdade"; ainda assim, uma afirmação como esta apenas resume uma proposição como "a liberdade como não interferência é, num sentido relevante, a concepção mais apropriada" dada sua justificação. Em resumo, conceitos servem de "tijolos" para a construção de princípios (proposições com conteúdo normativo ou avaliativo) que, por sua vez, servem a construção de teorias, estas compreendidas como um quadro de todas as implicações de princípios subjacentes (LIST; VALENTINI, 2016, p. 534-536).

5 A filosofia política então é compreendida como um "braço" da filosofia moral. Neste sentido Kymlicka (2006, p. 7-8); Berlin (2002b, p. 168) e Vincent (2004, p. 1). Resta, porém, como advertem List e Valentini (2016, p. 527), sob o risco de colapsar as disciplinas de filosofia moral e política, que se ofereçam critérios para o que contará como um problema "político"; a este respeito os autores identificam na literatura critérios substantivos e diferenças no que chamam de "condições de teorização".

6 Os filósofos políticos analíticos formam "escola" não por um comprometimento ideológico comum, mas pelas suposições acerca dos objetivos e métodos da teoria política entre outras características comuns que analisaremos mais a frente (DAGGER; MILLER, 2008, p. 446). Além disso, apesar de pertencerem ao contexto da filosofia analítica, a relação entre a filosofia política analítica contemporânea e os fundadores da filosofia analítica como Frege, Russell, Moore e Wittgenstein não é óbvia (WOLFF, 2013). Num sentido histórico, a filosofia analítica é uma corrente filosófica surgida ao final do século XIX e desenvolvida ao longo de todo o XX, sobretudo nos países anglo saxões, como reação ao idealismo filosófico; possui como ideia básica a concepção de que a filosofia para resolver suas questões, deve realizar-se pela análise da linguagem (ou dos conceitos); contudo, é importante ressaltar que a tradição analítica é composta de várias linhas que se diferenciam, justamente, no que se entende por análise e o objeto desta (MARCONDES, 2004, p. 7-14).

7 Para um bom panorama da disciplina no Brasil cf. Araujo e Assumpção (2010) e Ferraz (2004).

8 Como nos mostra Andrew Vincent (1997, p. 16), a ideia de uma "tradição" de teóricos da política ao longo da história é uma invenção do século XX lançada sobre uma série de autores diferentes para que estes nos falem coerentemente. Em todo caso, é de se notar, portanto, a longevidade do campo e, justamente por isso, sua pluralidade metodológica e em termos de conclusões substantivas (LIST; VALENTINI, 2016, p. 525). 
ser criticadas, têm preocupado aos filósofos. Com uma história tão longa, a reflexão normativa passou por muitas mudanças e crises, entre as quais, talvez a mais séria, tenha ocorrido ao longo da primeira metade do século XX no clima filosófico promovido pelo positivismo lógico.

Pela reconstrução histórica de Steve Buckler (2002, p. 172-176), sob a égide do positivismo lógico as questões normativas da filosofia política tornaram sem sentido. Isso porque promoveu-se uma verdadeira reavaliação das bases do que se entendia por conhecimento válido ou objetivo com a separação entre fato e valor (uma distinção de origem humeana). Por essa distinção, todo conhecimento possível do mundo provinha de generalizações de experiências empíricas particulares, até mesmo as abstrações. A única outra forma de conhecimento válido seria a lógica, advinda do conhecimento matemático, pela qual se organizariam as relações entre as ideias oriundas da experiência.

Sendo os fatos nossa única fonte confiável de conhecimento, que nos informariam apenas como o mundo é e não como deveria ser, qualquer juízo de valor passou a ser considerado irracional, apenas uma expressão emotiva convencional. Questões sobre a melhor ordem política convidando ao exame moral foram consideradas erros quanto ao que se entendia por conhecimento válido ou objetivo.

É fácil perceber o quanto ficou restrita a atividade da filosofia política neste cenário. Erradicando todas as questões consideradas "especulativas" e "ilusórias" da filosofia, a exemplo das questões tradicionais da filosofia política, ao filósofo, portanto, caberia apenas um papel limitado diante das descobertas da ciência. Estando a investigação empírica na província da ciência, ao filósofo restaria apenas a investigação, no plano da lógica, das relações entre conceitos; basicamente uma tarefa de análise linguística.

Confinado o filósofo político à clarificação dos conceitos políticos advindos da experiência empírica, o estudo por excelência da política logo passou, já na metade do século XX, para a ciência política centrada na investigação dos fatos, considerado expressado no comportamento político, conforme a visão - ainda no paradigma positivista - da denominada Revolução Behaviorista.

Foi neste clima intelectual que apareceu, na introdução de 1956 - no primeiro volume de uma coletânea ${ }^{9}$ - a famosa sentença de morte da disciplina dada por Peter Laslett,

9 A coletânea em questão é a Philosophy, Politics and Society organizada pelo próprio Peter Laslett de 1956 até 2003. As apresentações de cada volume ao longo das décadas dão o testemunho do desenvolvimento da disciplina na segunda metade do século XX como nos mostra Jonathan Wolff (2013, p. 801-812). 
segundo o qual, a tradição que vem de Hobbes a Bosanquet foi interrompida; e assim, a filosofia política estava morta10 (LASLETT, 1956, p. vii).

\section{$O$ revigoramento da teorização normativa na segunda metade do século $\mathrm{XX}$}

Ainda conforme a reconstrução histórica de Steve Buckler (2002, p. 176-180), coube a Wittgenstein uma importante alternativa ao positivismo lógico no plano da epistemologia. Contrariando o projeto do positivismo lógico, incluídos seus próprios estudos iniciais, Wittgenstein passou a duvidar que a linguagem tivesse significado quando expressasse ou "mapeasse" os elementos sensíveis de uma experiência prévia.

Em contraste, propunha que a linguagem, na realidade, era ela própria a responsável pelo caráter cognoscível do mundo. Nessa visão, a linguagem constitui a realidade e qualquer atividade de análise da linguagem pela filosofia deveria recair não só sobre a linguagem oriunda do discurso científico, mas também sobre as várias outras formas pelas quais, também, o mundo se torna inteligível como as artes, religiões e ideologias.

Em certo sentido, portanto, essa mudança de perspectiva na filosofia analítica, conhecida como "virada pragmática", ocasionada entre outros por Wittgenstein, promoveu a teorização normativa ao incluir novamente o elemento normativo como parte no horizonte das análises filosóficas das linguagens constitutivas da realidade inteligível. A força normativa presente na linguagem moral e política passa a ser novamente levada a sério.

No plano específico da teoria política, como presciente resposta a proclamação de morte dessa disciplina, na Inglaterra, Isaiah Berlin (2002a), em seu ensaio original de 1962, Ainda existe teoria política?, argumentou contra o reducionismo positivista do conhecimento válido (empírico ou lógico) pontuando a existência de questões que não podem ser resolvidas nos moldes das ciências naturais ou formais, tais como as da filosofia política.

10 Certamente essa afirmação de Laslett é um diagnóstico exagerado ao levarmos em conta, como nos lembra Bikhu Parekh (1998, p. 504-506), que é no período das décadas de 50 e 60 que encontramos a produção de importantes autores da filosofia política como Hannah Arendt, Karl Popper, Leo Strauss, Eric Voegelin, Habermas, Marcuse, Altusser, Oakeshott entre outros. 
Como observa Dworkin, a importância de Isaiah Berlin no renascimento da teoria política normativa é evidenciada no potencial teórico de outro famoso ensaio, de 1958, Dois conceitos de liberdade, quando provoca de imediato, "continuing, heated and mainly illuminating controversy" tornando-se, ainda em suas palavras, "a staple of graduate and undergraduate reading lists, as it still is" (DWORKIN, 1991, p. 100). Somado a esse clima filosófico favorável ao pensamento normativo, ao longo da segunda metade do século XX, nos deparamos com outro ingrediente importante na direção de teorizações normativas mais ambiciosas, o que lan Shapiro, emprestando o termo de Bernard Williams, chamou "urgência política", isto é, "temores de que as instituições existentes enfrentam ameaças poderosas e que as práticas prevalecentes estejam a sofrer mudanças profundas", situação essa apta a gerar solo fértil para a especulação sobre os fundamentos da política e combustível para o engajamento (SHAPIRO, 1990, p. 3, tradução nossa).

Novas ameaças pairavam no contexto da segunda metade do século XX. A realidade das armas nucleares na guerra fria mostrou a imprecisão de qualquer fé utilitarista perspectiva moral até então dominante na filosofia política - na obsolescência dos problemas morais promovido pelo avanço técnico da humanidade. Ficava cada vez mais clara a necessidade da discussão dos fundamentos morais de novas ideias: os direitos humanos e os crimes contra a humanidade invocados nos julgamentos de Nuremberg, a questão dos crimes de guerra em face da guerra do Vietnã e as reivindicações dos movimentos de direitos civis nos EUA são alguns exemplos que convidavam ao pensamento de maior envergadura quanto aos fundamentos morais da política.

Neste cenário, precisamente em 1971, surge o livro de John Rawls reacendendo agora no contexto americano - a possibilidade de um pensamento filosófico respeitável sobre os fundamentos da associação política (SHAPIRO, 1990, p. 5-7). Uma Teoria da Justiça logo se tornou objeto de controvérsias, por exemplo, nos debates com os comunitaristas, libertários, feministas, multiculturalistas, utilitaristas, enfim, transformou o cenário intelectual de tal forma que não pode ser ignorada: o argumento rawlsiano catalisou uma explosão de teorização acadêmica sobre os fundamentos morais da política.

Atestando o revigoramento da teoria política de primeira ordem, outros volumes da coletânea de Peter Laslett revelando a boa saúde da disciplina, seguiram-se ao primeiro de 1956. Também novos periódicos como Political Theory, History of Political Thought e Philosophy and Public Affairs, e cadeiras em filosofia política foram criadas 
nos departamentos de ciência política, filosofia e direito (SHAPIRO, 1990, p. 7; WOLFF, 2013, p. 812-813).

A importância do pensamento normativo restou, assim, evidente para muitos. Como advertiu Berlin (2002b, p. 228), negligenciar a teoria política por seu objeto instável é estar "à mercê de crenças políticas primitivas e não criticadas". Considerar as instituições sociais e os arranjos políticos sem a reflexão dos princípios organizadores adequados pode até levar a um entendimento de seu funcionamento, mas escassamente ajudará a informar um julgamento de adequação e desejabilidade (HELD, 1991, p. 17).

É aí que a teoria política normativa se apresenta como um meio para um tratamento lógico rigoroso de nossas "opções morais". Certamente não teremos a certeza de que a mudança promovida pela teoria política será sempre para melhor, visto que as opções são inúmeras e nem sempre as melhores. Em todo caso, ocupar-se da teorização normativa é partir da esperança de que os atores morais que debatem suas opções de forma aberta e consciente cometerão, ao final, menos o que a maioria das pessoas reprovaria do ponto de vista moral do que aqueles que procedem irrefletidamente ou suprimem o debate moral (GLASER, 1995, p. 34).

\section{As características da Teoria Política Normativa Analítica}

Como vimos, sob a égide do clima filosófico do positivismo lógico a filosofia analítica ganhou essencialmente duas características: a aversão às questões metafísicas da filosofia tradicional e o papel de "segunda ordem" de clarificação conceitual do material de "primeira ordem" advindo das investigações científicas. A partir da "virada pragmática", no entanto, a primeira característica foi mantida e a segunda sofreu uma alteração (VINCENT, 2004, p. 108-109).

Ao se considerar a linguagem como constitutiva de um mundo sempre interpretável, os conceitos normativos passam a ser fundamentais, já que são elementos constitutivos no todo da linguagem que empregamos, assim, podem e devem ser parte da análise conceitual do filósofo. Numa expressão de Isaiah Berlin (2002b, p. 227), restou reconhecido o "poder das ideias".

Como analisa Andrew Vincent (2004, p. 109), esse foi um primeiro "impulso" na direção de um revigoramento do pensamento normativo. O segundo viria com o pensamento 
rawlsiano trazendo explicitamente uma teoria e sua justificação, ou seja, pretendendo mostrar, mediante o oferecimento de razões, o porquê devemos adotar uma estrutura de normas ao invés de outras. À claridade promovida pela atividade de análise conceitual somam-se, então, princípios e teorias com suas justificativas e evidências rigorosamente argumentadas (LIST; VALENTINI, 2016, p. 534-536). Um princípio ou teoria poderiam, agora, pela argumentação, serem vistos como mais de acordo, por exemplo, com nossas intuições morais cotidianas que outras apresentações ${ }^{11}$.

Central para entender melhor a característica de ser "normativa" (e avaliativa) que a teoria política readquire, é este conceito de justificação. Justificar algo é apresentar razões para valorizar algo. Valorizar é mais forte que "preferir" ou "gostar"; trata-se de apresentar razões gerais para o apoio ou recusa de determinada prática política, mostrar seu valor de forma racional e imparcial (aceitável pelos outros). Mas como podemos saber se possuímos razões imparciais? Como podemos dizer se os argumentos usados para justificar são bem-sucedidos?

Essa questão poderia ser respondida afirmando-se o sucesso de um argumento na medida em que ele de fato persuade. Por outro lado, o simples persuadir de um argumento não implica que as razões apresentadas sejam boas. Assim, persuasão efetiva e justificativa são coisas distintas. $\bigcirc$ que se quer saber não é se as pessoas são persuadidas pelo argumento, mas se o deveriam ser s. $^{12}$ IRD, 2006, p. 13-14).

11 Importa destacar que, nas questões normativas da política, o fato de não encontrarmos consenso não segue a impossibilidade ou arbitrariedade dos julgamentos valorativos. Ainda é possível entre pessoas "razoáveis" que julgamentos sejam mais convincentes ou justificáveis que outros:"[...] entre o conhecimento causal e o lógico-dedutivo, de um lado, e a ignorância, de outro, há lugar para o julgamento" (VITA, 2008, p. XVII-XVIII), e julgamentos podem ser piores ou melhores. Ou, de outra forma, razões são oferecidas "[...] o que na teoria política normativa denominamos uma 'justificação' - para mostrar que uma dada configuração de valores como sendo mais aceitável ou mais razoável do que outra e, nesse caso, a discussão vai girar em torno dos méritos dessa justificação" (VITA, 2008, p. XVIII-XIX). Quanto ao termo "razoável", faz parte do paradigma rawlsiano. Evitando-se a noção de verdade na teoria política, o termo razoável se apresenta como menos "carregado" e pode ser interpretado de forma epistemológica e/ou moral (LIST; VALENTINI, p. 547-549); reconhecendo as dificuldades em dar contornos da ideia, Rawls (2011, p. 63-65) busca expressá-la em torno de dois aspectos dos cidadãos de uma democracia constitucional: (a) a disposição de propor e sujeitar-se a termos equitativos de cooperação e (b) disposição de reconhecer os limites da capacidade do juízo, limites de ordem epistemológica. Em síntese, o razoável é atributo da doutrina que "[...] não rejeita os princípios fundamentais de um regime democrático" (RAWLS, 2011, p. XVII).

12 Os teóricos ao discutirem as questões substantivas da política são levados, portanto, a questões fundantes sobre o critério racional base da avaliação moral. No que ele consiste? É um artefato inscrito nos próprios sujeitos? É um produto das comunidades e convenções humanas? Assim, esse apelo a razões morais para se valorizar determinada prática política leva a uma série de posições metaéticas, entre as quais, as manifestações teóricas políticas de maior destaque no cenário contemporâneo são as do utilitarismo, do liberalismo deontológico e o comunitarismo (GLASER, 1995, p. 23). List e Valentini (2016, p. 537-538) alertam para a diferença entre as (a) formulações dos conceitos, princípios e teorias, daquilo que se oferece em suporte destes enquanto (b) justificação e evidência, e dos (c) mecanismos de avaliação da "verdade" ou "aceitabilidade" de (a) e (b). No que tange aos mecanismos de avaliação (que também servem para a operação de justificação), List e Valentini (2016, p. 538) diferenciam critérios internos (avaliação de formulação e estrutura lógica) e externos (avaliação da adequação ao conteúdo normativo que se pretende representar, o "algo externo" da teoria); é de se notar, mais uma vez, que a avaliação externa dependerá de um posicionamento metaético.

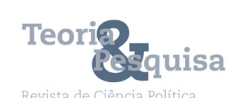


Podemos ver bem como a característica da (a) normatividade se encaixa perfeitamente com a do (b) rigor conceitual: a clarificação dos conceitos é preliminar à justificação normativa. É necessário, por exemplo, que se tenha claro o que se entende por democracia ou conceitos relacionados se quisermos dar razões de seu valor (DAGGER; MILLER, 2008, p. 447) ${ }^{13}$.

Duas outras características são dignas de nota por informarem as teorizações normativas da abordagem analítica. Como ressaltamos, um aspecto do positivismo lógico permaneceu intacto, qual seja, a (c) aversão metafísica. Contemporaneamente, as justificativas normativas baseadas em verdades metafísicas absolutas são vistas com grande suspeita, o que equivale a dizer que os fundamentos dos argumentos justificatórios tendem a ser enquadrados em termos mais modestos, sobretudo pelo (d) reconhecimento do pluralismo.

Pode-se dizer que quase todos os teóricos políticos analíticos contemporâneos, de várias formas, lidam com o fenômeno do pluralismo (DAGGER; MILLER, 2008, p. 448). Isso quer dizer, reconhecem que as questões decisivas da política envolvem a consideração de um número aparentemente grande de visões que conflitam e que sugerem, cada qual, uma resposta diferente a essas questões ${ }^{14}$.

Por fim, a teoria política analítica contemporânea deve ser descrita como majoritariamente (e) liberal de forma ampla (contra um sentido estrito de uma visão particular dos direitos individuais ou da extensão específica do Estado); tem por objetivo prático estabelecer os princípios políticos aptos a orientar a leitura, avaliação e feitura de Constituições e políticas públicas de Estados Liberais onde os cidadãos são livres e iguais para fazerem escolhas de como sua sociedade deve ser organizada. O pressuposto é o de que os teóricos falam, para além dos outros teóricos, a uma comunidade moral de cidadãos nacionais ou de contextos mais amplos (DAGGER; MILLER, 2008, p. 449).

13 Outro exemplo é apresentado por List e Valentini (2016, p. 530, tradução nossa): "[...] qualquer teoria do liberalismo deverá empregar um conceito de liberdade"; desta forma, a análise de conceitos se apresenta, em algum sentido, como o "mínimo" normativo e avaliativo da atividade teórica normativa: quando avaliamos conceitos como liberdade ou democracia geralmente estamos interessados naqueles que achamos valorosos (normativamente requeridos), para então, construirmos princípios e teorias. List e Valentini apresentam, também, uma lista ilustrativa do que, geralmente de forma implícita, os teóricos consideram como requisitos de um bom conceito (LIST; VALENTINI, 2016, p. 532-534).

14 Algo de nota na teoria política contemporânea é a intensificação da sensibilidade com relação à questão da diversidade, algo a ser levado em conta para quase todo projeto justificatório liberal (EVANS, 2001, p. 11). Posta a relevância política da diversidade, observa Bhikhu Parekh (2003, p. 239), vários autores têm reinterpretado, refinado ou redefinido o liberalismo, no sentido de torná-lo mais hospitaleiro a pluralidade cultural e moral. Neste cenário ganham relevo a formulação clássica da ideia de "pluralismo de valores" de Isaiah Berlin e o "fato do pluralismo" de Rawls. 
Feito um breve percurso histórico e uma caracterização geral da abordagem analítica15, voltemos à questão do método na teoria política normativa.

\section{O método como estratégia/estilo}

Para além do campo estritamente científico, lugar do método "ideal" por excelência que acima caracterizamos como algoritmo, o método apresenta-se como estratégia, ou no caso da filosofia, Granger também fala em estilo. Como aponta (GRANGER, 1992, p. 69-70), muitos dos grandes filósofos, de fato, reivindicaram um método como um dos aspectos mais importantes de suas contribuições; por exemplo, Platão descrevendo o método socrático, a dúvida metódica de Descartes, o método dialético de Hegel, ou, ainda, o método fenomenológico de Husserl.

Certamente essa multiplicidade de métodos nos mostra que "[...] não se trata aqui do método no sentido em que a ciência autoriza a defini-Io" (GRANGER, 1992, p. 70). Contrariamente ao pensamento científico, para Granger (1992, p. 69-70), o projeto da filosofia, quaisquer que sejam suas formas e objetivos, é estabelecer uma relação entre a experiência vivida e os conceitos num sistema, mesmo que não explícito.

A estratégia, ou estilo, toma aqui o lugar do método e faz parte do próprio conteúdo de uma filosofia: toda filosofia "não é mais que um 'método', através do qual um indivíduo se propõe estabelecer uma relação entre o vivido e os conceitos" (GRANGER, 1992, p. 70). Também seguem essa ideia Folscheid e Wunenburger, ao discorrerem sobre o assunto:

Só é possível adquirir métodos de trabalho em filosofia se antes for compreendido que o método é inerente à própria filosofia. Elaborar uma metodologia, com efeito, já é fazer filosofia, já que isso envolve necessariamente uma concepção filosófica da filosofia.

15 Importa assinalarmos duas linhas de críticas, entre outras, que a abordagem analítica tem recebido. Floyd e Stears (2011, p. 1) identificam que entre as principais críticas feitas à filosofia política nos últimos quarenta anos, a de sua suposta ahistoricidade tem sido proeminente, entre os "acusadores" incluem: Isaiah Berlin, John Dunn, Raymond Geuss, John Gray, Charles Larmore, Alasdair MacIntyre, Richard Rorty e Judith Shklar, Quentin Skinner, James Tully e Bernard Williams. Em coletânea destinada a investigar, portanto, as relações entre a história e a filosofia política, Floyd e Stears (2011, p. 2-4) observam o aparecimento de dois temas que desafiam a filosofia política: o lugar do universalismo e do realismo na disciplina. Pelo "desafio universalista", o debate gira em torno da identificação da moral como algo universal ou como pluralidade de códigos locais: a tarefa, portanto, é decidir onde situar a filosofia política no espectro que vai do universalismo ao contextualismo. Já o "desafio realista" traz o debate sobre o grau de ambição que os filósofos políticos devem perseguir em suas formulações: devem buscar elementos atemporais da política - caso existam, ou as características da política no aqui e agora de práticas concretas? Assim, nesta chave de debates a tarefa é situar a filosofia política no espectro que vai do utopismo ao pessimismo. Como mostram os autores, no desafio realista duas questões são colocadas: "O que" se deseja atingir com a filosofia política e "como" devemos atingir este objetivo. Nesta chave podemos incluir o debate que ficou conhecido como da Teoria Ideal versus Teoria Não-Ideal (VALENTINI, 2012). 
[...] O método obedece a uma necessidade interna e não a um capricho vindo de alguma outra parte. Seria inútil, portanto, esperar dominar técnicas se não se compreende a razão de ser que está inscrita no modo de pensar filosófico. Por isso a metodologia filosófica não tem existência em si, autonomia em relação à disciplina; ao contrário, ela se confunde com o conjunto das exigências teóricas e especulativas do ato de filosofar, cujo objetivo é dar às ideias e à reflexão o mais obstinado rigor e a maior perfeição possível (FOLSCHEID; WUNENBURGER, 2006, p. VIII).

No mesmo sentido, agora no caso específico da teoria política normativa, observa Will Kymlicka em obra introdutória da disciplina:

É comum, em um livro deste tipo, dizer-se algo a respeito da metodologia, de como compreendemos o empreendimento da filosofia política, do que a distingue de outros empreendimentos intelectuais, como a filosofia moral, e de como procedemos para julgar o seu sucesso. Não direi muito a respeito dessas questões aqui, em parte porque não acho que haja muito que se possa dizer em um nível geral. Cada uma das teorias examinadas a seguir responde a essas perguntas de maneira diferente - cada uma oferece seu próprio ponto de vista sobre a divisão da filosofia moral e filosofia política e suas próprias considerações sobre os critérios da argumentação bem-sucedida (KYMLICKA, 2006, p. 7).

Assim, logo se vê o equívoco de qualquer formulação dogmática de técnicas, o que poderia levar a pensar que existe um único método, "o" método, para todo exercício filosófico, cuja aplicação cega e mecânica, garantiria um sucesso infalível (FOLSCHEID; WUNENBURGER, 2006, p. VIII; GRANGER, 1992, p. 70). Neste momento poderíamos nos perguntar: mas qual o critério, então, para se avaliar o sucesso de uma filosofia?

Não devemos pensar, decerto, que na ausência de um método como algoritmo, tudo é permitido! Certamente em filosofia não se fala em verdade demonstrável, universalmente atingível, mas cada um dos estilos filosóficos históricos gera critérios de validade dos seus próprios produtos, aos quais em determinada época ou sociedade, os indivíduos serão mais ou menos sensíveis (GRANGER, 1992, p. 70).

O leitor atento e crítico sempre poderá discernir se seu autor é fiel à própria norma de validade, sé é um filósofo rigoroso ou não: o rigor consiste em limitar-se aos pressupostos e princípios estabelecidos. Desta forma, pode-se falar não de filósofo falso, mas de filósofo falho. 
Quanto à feitura de filosofia, Granger (1992, p. 70) aponta que o leitor atento e apaixonado, se aderir ao propósito de um filósofo,"imita e revive o seu caminho, analisa-o e descobre os seus pressupostos, se também ele quer ser um filósofo". Da mesma forma em Folscheid e Wunenburger (2006, p. VIII): "[...] ao praticar exercícios de filosofia, trata-se de impregnar-se ainda mais de filosofia e, finalmente, de melhor filosofar".

\section{Considerações finais}

Feitas essas considerações e cotejando com o que dissemos nas seções anteriores sobre a teoria política normativa, especificamente no tocante à natureza filosófica de suas questões e suas características gerais no caso de uma abordagem analítica, parece plausível que, ao pensarmos sobre o método nessa disciplina, seja possível recorrer-se à ideia de um estilo norteador tal como entendido acima. Nesse caso, indispensável é, à tarefa do teórico, a compreensão e explicitação de características gerais e pressupostos que ditam o espírito da abordagem, tal como algumas que apresentamos, se pretende oferecer contribuição "válida" aos debates que ocorrem nesta área.

Em síntese, no presente trabalho investigamos a questão da possibilidade de se falar em método na disciplina de teoria política, entendida de forma específica como teoria política normativa ou filosofia política contemporânea. O resultado geral da investigação propõe, ao final, que não podemos falar num método científico, considerando a natureza filosófica da disciplina, mas, ainda sim, podemos falar em método se compreendermos esta ideia nos moldes daquilo que Granger chamou de método como estratégia ou estilo; algo que norteia, traz balizas e possibilita a comunidade de debate nesta disciplina. Ao chamarmos atenção para isso, esperamos ter contribuído, de alguma forma, em qual direção esta agenda emergente deverá seguir e de qual limite deverá, ao nosso entender, desde o início, estar claro: no caso, a impossibilidade da pretensão de um método algoritmo, aquele que fornece uma receita detalhada do que deverá ser feito, como encontramos no método científico, para a teoria política normativa; também esperamos ter ressaltado que essa impossibilidade não retira em absoluto a ideia de rigor e importância das contribuições da teoria política normativa para o pensamento político em geral. 


\section{Referências}

ARAUJO, C.; ASSUMPÇÃO, S. R. Teoria Política no Brasil hoje. In: MARTINS, C. B.; LESSA, R. (Ed.). Horizontes das Ciências Sociais no Brasil: Ciência Política. São Paulo: Barcarolla/ANPOCS, 2010. p. 51-85.

BERLIN, I. Ainda existe a teoria política? In: HARDY, H.; HAUSHEER, R. (Ed.). Isaiah Berlin: estudos sobre a humanidade. São Paulo: Companhia das Letras, 2002a. p. 99-158.

BERLIN, I. Dois conceitos de liberdade. In: HARDY, H.; HAUSHEER, R. (Ed.). Isaiah Berlin: estudos sobre a humanidade. São Paulo: Companhia das Letras, 2002b. p. 226-272.

BIRD, C. An introduction to political philosophy. Cambridge: Cambridge University Press, 2006.

BUCKLER, S. Normative theory. In: MARSH, D.; STOKER, G. (Ed.). Theory and methods in political science. 2. ed. New York: Palgrave Macmillam, 2002. p. 173-194.

DAGGER, R.; MILLER, D. Utilitarianism and beyond: contemporary analytical political theory. In: BALL, T.; BELLAMY, R. (Ed.). The Cambridge history of twentieth-century political thought. Cambridge: Cambridge University Press, 2008. p. 446-469.

DWORKIN, R. Two concepts of liberty. In: MARGALIT, E.; MARGALIT, A. (Ed.). Isaiah Berlin: a celebration. Chicago: Chicago University Press, 1991. p. 100-109.

FERRAZ, S. Os dados normativos: apontamentos sobre a recepção das teorias contemporâneas de justiça no Brasil (1990-2003). Revista Brasileira de informação Bibliográfica em Ciências Sociais, v. 58, p. 131-157, 2004.

FLOYD, J.; STEARS, M. Introduction. In: FLOYD, J.; STEARS, M. (Ed.). Political philosophy versus history? Contextualism and real politic in contemporary political thought. Cambridge: Cambridge University Press, 2011. p. 1-9.

FOLSCHEID, D.; WUNENBURGER, J. Metodologia filosófica. São Paulo: Martins Fontes, 2006.

FRAZER, M. Three methods of political theory: historicism, ahistoricism and transhistoricism. In: ANNUAL MEETING, 2010, Canada. Canada: Canadian Political Science Association, 2010. Disponível em: <https://www.cpsa-acsp.ca/papers-2010/Frazer.pdf>. Acesso em: 2 dez. 2016.

GLASER, D. Normative theory. In: MARSH, D.; STOKER, G. (Ed.). Theory and methods in political science. 1. ed. New York: Palgrave Macmillam, 1995. p. 21-41.

GRANGER, G. G. Método. In: ROMANO, R. (Ed.). Enciclopédia Einaudi. Lisboa: Imprensa NacionalCasa da Moeda, 1992. v. 21. p. 55-71.

GUNNELL, J.G. Political theory and political science. In: MILLER, D. (Ed.). The Blackwell Encyclopaedia of Political Thought. Oxford: Blackwell Publishers, 1987. p. 386-390.

HELD, D. Editor's introduction. In: HELD, D. (Ed.). Political theory today. Oxford: Blackwell Publishers, 1991. p. 1-21.

KYMLICKA, W. Filosofia política contemporânea: uma introdução. São Paulo: Martins Fontes, 2006. 
LASLETT, P. Introduction. In: LASLETT, P. (Ed.). Philosophy, politics and society. Oxford: Blackwell, 1956. p.vii-xv.

LEOPOLD, D.; STEARS, M. Introduction. In: LEOPOLD, D.; STEARS, M. (Ed.). Political theory: methods and approaches. Oxford: Oxford University Press, 2008. p. 1-10.

LIST, C.; VALENTINI, L. The methodology of political theory. In: CAPPELEN, H.; GENDLER, T. S.; HAWTHORNE, J. (Ed.). The Oxford Handbook of Philosophical Methodology. Oxford: Oxford University Press, 2016. p. 525-553.

MARCONDES, D. Filosofia analítica. Rio de Janeiro: Jorge Zahar, 2004.

PAREKH, B. Political theory: traditions in political philosophy. In: GOODIN, R..; KLINGEMANN, H. D. (Ed.). A new handbook of political science. Oxford: Oxford University Press, 1998. p. 503-518.

PAREKH, B. Contemporary liberal responses to diversity. In: MATRAVERS, D.; PIKE, J. E. (Ed.). Debates in contemporary political philosophy: an anthology. New York: Routledge, 2003. p. 239-247.

RAWLS, J. O Liberalismo Político. São Paulo: Martins Fontes, 2011.

SHAPIRO, I. Political criticism. Berkeley: University of California Press, 1990.

STOKER, G. Introduction. In: MARSH, D.; STOKER, G. (Ed.). Theory and methods in Political Science. 1. ed. New York: Palgrave Macmillam, 1995. p. 1-18.

VALENTINI, L. Ideal Vs. Non-ideal theory: a conceptual map. Philosophy Compass, v. 7, n. 9, p. 654-664, 2012.

VARGAS-MACHUCA, R. La filosofía política como teoría política normativa. Revista Española de Ciencia Política, v. 8, p. 47-70, 2003.

VINCENT, A. Introduction. In:VINCENT, A. (Ed.). Political theory: tradition and diversity. Cambridge: Cambridge University Press, 1997. p. 1-27.

VINCENT, A. The nature of political theory. New York: Oxford University Press, 2004.

VITA, A. Apresentação da Edição Brasileira. In: RAWLS, J. Uma teoria da justiça. 3. ed. São Paulo: Martins Fontes, 2008. p. XI-XXXIII.

WOLFF, J. Analytic political philosophy. In: BEANEY, M. (Ed.). The Oxford handbook of the history of analytic philosophy. Oxford: Oxford University Press, 2013. p. 796-822.

Recebido: 07 jul., 2016

Aceito: 10 dez., 2016 